\title{
High-resolution unmanned aircraft systems imagery for stay-green characterization in grain sorghum (Sorghum bicolor L.)
}

\author{
Isaac Barnhart $\odot,{ }^{a}$ Paula Demarco,,${ }^{\text {a }}$ P. V. Vara Prasad $\odot,{ }^{\text {a,b }}$ Laura Mayor, ${ }^{c}$ \\ Mithila Jugulam $\odot,{ }^{a}$ and Ignacio A. Ciampitti $\odot^{\mathrm{a}, *}$ \\ ${ }^{a}$ Kansas State University, Department of Agronomy, Manhattan, Kansas, United States \\ ${ }^{\mathrm{b}}$ Kansas State University, Sustainable Intensification Innovation Lab, Manhattan, \\ Kansas, United States \\ ${ }^{c}$ Corteva Agriscience, Wamego, Kansas, United States
}

\begin{abstract}
Grain sorghum (Sorghum bicolor [L]. Moench) is a crucial crop to the world's semiarid regions, as it can produce grain and biomass yields in precipitation-limited environments. Many genotypes have a characterized form of drought resistance known as the stay-green (SG) trait, enabling sorghum plants to resist postflowering drought stress that can severely reduce yields. Breeding for SG sorghum lines is considered vital for sorghum breeders around the world, but selecting for SG traits currently relies on methods that are labor-intensive and timeconsuming. Using unmanned aerial systems capable of capturing high-resolution imagery offers a solution for reducing the time and energy required to select for these traits. A field study was conducted in Manhattan, Kansas, where 20 Pioneer $^{\circledR}$ sorghum hybrids were planted in a randomized complete block design with three replications per hybrid. Imagery was collected with a DJI ${ }^{\circledR}$ Matrice $200^{\mathrm{TM}}$ equipped with a MicaSense ${ }^{\circledR}$ RedEdge-MX ${ }^{\mathrm{TM}}$ multispectral camera. Flight altitude was $30 \mathrm{~m}$, and flights were collected under clear, sunny skies within $\pm 2.5 \mathrm{~h}$ of solar noon. Ground-measured data included visual senescence ratings, fresh and dry plant biomass, leaf area index, and final grain yield. After correlation and regression analysis, results indicated significant relationships with the near-infrared spectral band with fresh and dry plant biomass samples, the green normalized difference vegetation index scores at flowering were the most related to final grain yield, and the visible atmospherically resistant index was the most related to visual senescence scores. Significant spectral band/vegetative indices were clustered into groups, and significant differences were found between various traits. We have developed a methodology for SG sorghum growers to collect, process, and extract data for more efficient identification of traits of interest. (1) The Authors. Published by SPIE under a Creative Commons Attribution 4.0 International License. Distribution or reproduction of this work in whole or in part requires full attribution of the original publication, including its DOI. [DOI: 10.1117/1.JRS.15.044501]
\end{abstract}

Keywords: biomass; crop breeding; grain sorghum; leaf area index; remote sensing; senescence; stay green.

Paper 210249 received Apr. 20, 2021; accepted for publication Sep. 13, 2021; published online Oct. 5, 2021.

\section{Introduction}

In the year 2050, the human population is expected to rise from 7 to 10 billion people, consequently increasing global demand for food. ${ }^{1}$ To meet these increasing demands, current global crop production will need to be at least doubled. ${ }^{2}$ Even though there are nearly 200 species of plants are used for wide-scale human consumption, there are growing concerns that current farming practices and crop cultivars will not be capable of meeting these demands. ${ }^{1}$ Major crops, including corn (Zea mays), rice (Oryza sativa L.), and wheat (Triticum aestivum), displayed an annual yield of improvement from $0.8 \%$ to $1.2 \%$, but this yield trend must be doubled to meet future demands. ${ }^{1,3}$ In addition, several regions around the world have experienced yield losses due to stresses brought by a warming climate, ${ }^{4}$ further complicating the goal of increasing yields.

*Address all correspondence to Ignacio A. Ciampitti, ciampitti@ksu.edu 
To address these challenges, crop breeders must select for cultivars for increased yield potential while simultaneously displaying stability against environmental stressors such as drought and temperature stress. ${ }^{5}$

One crop that shows potential to contribute to and diversify human diets is grain sorghum (Sorghum bicolor [L.] Moench). ${ }^{1}$ Grain sorghum is a $\mathrm{C} 4$ crop that is an important food source for many people in Africa, Asia, and Central America. ${ }^{6}$ Globally, it is the fifth most important cereal crop, after wheat, corn, rice, and barley (Hordeum vulgare) ${ }^{7-9}$ and is also valued for its use for forage and biofuel production. ${ }^{10}$ Since it is known to have originated in sub-Saharan Africa, ${ }^{11,12}$ it is well adapted to semi-arid and arid regions of the world, making it a crop of choice in areas with limited precipitation. ${ }^{69}$ Despite having distinct economic and yield advantages over corn in drier environments, ${ }^{13,14}$ sorghum is still considered to be well below its yield potential. ${ }^{15}$ This is partially because grain sorghum is widely considered to be difficult to process into products for human consumption, so as a result, most grain sorghum grown in developed countries is exported and used as animal feed. ${ }^{15}$ However, as many areas in the world are predicted to become warmer and drier due to climate change, it is estimated that more regions will adapt to this by growing more grain sorghum for human consumption. ${ }^{15}$ Being well-suited for arid environments, sorghum is considered a crop that will help with the goal of global food security under future climate changes. ${ }^{10,16}$

One way sorghum breeders are looking to combat yield losses is to select for cultivars tolerant to abiotic stress, particularly in terms of drought tolerance. ${ }^{17,18}$ All stresses considered, one of the most relevant stressors to sorghum is post-flowering drought stress, often known as "terminal drought."7 This type of stress severely limits grain filling during later growth stages, impacting the duration of this period and thus severely reducing grain yields. Many genetic lines of crops, including grain sorghum, have a characterized form of drought tolerance during postflowering growth stages known as the nonsenescence or "stay-green" (SG) trait. ${ }^{13,19}$ Grain sorghum genotypes with the SG trait continue to fill their grain under drought and also exhibit tolerance to several factors that affect grain sorghum under moisture stress such as stem rot and lodging. ${ }^{13,20-24}$ In addition to yield retention, the SG trait is valuable for biomass production in regions where water is limited, ${ }^{25,26}$ allowing farmers in these regions to produce more aboveground biomass for forage and biofuel production. Due to these advantages, many breeders consider the SG trait of much agronomic importance and has been and continues to be subjected to intensive selection in crop breeding trials. ${ }^{27}$

With these predicted changes to world population and climate patterns, there is an increasing amount of pressure on farmers and crop breeders to improve crop cultivars. ${ }^{28}$ As concerns arise regarding cultivar improvements beginning to plateau, ${ }^{1}$ new technologies are needed to boost the speed of cultivar selection in breeding trials. Technology that is capable of screening thousands of lines for a desired trait is essential for this process. ${ }^{29}$ These technologies can be even more important when screening for SG traits, which can be very labor-intensive and time-consuming if scored with traditional methods (i.e., using visual leaf scoring systems or SPAD meters). ${ }^{23,30,31}$ For this purpose, many breeders have turned to screening large trials with remote sensing methods, utilizing nondestructive approaches to measure reflected electromagnetic radiation from plants. ${ }^{32}$ Through identifying changes in both the visible and invisible spectral bands, information regarding vegetation health and productivity can be detected and quantified. ${ }^{33}$ In addition, these individual bands can be combined into vegetative indices (VIs), which have been shown to be successful in estimating traits, such as (but not limited to) plant biomass, ${ }^{34}$ leaf area index $(\mathrm{LAI}),{ }^{35}$ leaf senescence, ${ }^{36}$ and final grain yield. ${ }^{37}$

Spectral data have been used to explain senescence in previous studies, as they have been deemed useful in the prediction of green leaf area during senescence. ${ }^{38}$ In most vegetative remote sensing applications, healthy vegetation is sensed by detecting the quantity of near-infrared (NIR) wavelengths emitted because of cellular refraction. ${ }^{39}$ In cases of vegetative senescence, NIR reflectance does not significantly decrease; instead, the degradation of chlorophyll results in the decrease of green electromagnetic reflectance and the rise of red electromagnetic reflectance. ${ }^{40}$ There is seldom a major change observed in the relation of green leaf area to NIR reflectance, but the relation between red reflectance and green leaf area changes substantially. ${ }^{41}$ In many studies, there is an emphasis on quantifying red edge (RE) reflectance, as reductions in this region have been shown to be related to reductions in chlorophyll during senescence. . $^{3,38,41-43}$ 
However, since there are significant spectral fluctuations across the entire visible electromagnetic spectrum, ${ }^{43}$ VIs quantifying the change of green light reflectance to the change of red light reflectance are thought to also be able to quantify vegetative senescence.

Because remote sensing platforms such as satellites may not currently provide the spatial or temporal resolution necessary for screening individual cultivars, ${ }^{44}$ unmanned aerial systems (UAS) equipped with consumer-grade cameras have been shown to be useful for obtaining very high-resolution imagery for agricultural purposes. ${ }^{45}$ In addition, UAS platforms are considered relatively inexpensive $\mathrm{e}^{46}$ and have recently become more accessible not only in cost but also in ease of use for data processing for both farmers and research programs. ${ }^{36}$ As UAS has been said to be an effective platform for high-throughput phenotyping operations, ${ }^{47}$ our hypothesis is that high-resolution UAS multispectral imagery is an effective alternative to time-consuming ground evaluation and selection of traits of interest in sorghum SG breeding trials.

The main objectives of this study are to (1) investigate whether significant differences can be detected from the clusters formed in this methodology and (2) test the relevancy of using individual spectral bands and red-green-blue (RGB) VIs versus VIs based on the invisible electromagnetic spectrum by developing regression models comparing ground-sampled plant traits to spectral data.

\section{Materials and Methods}

\subsection{Study Area}

This study was conducted at the Corteva Agriscience ${ }^{48}$ grain sorghum nursery in Manhattan, Kansas $\left(39^{\circ} 9^{\prime} 13.69^{\prime \prime} \mathrm{N}, 96^{\circ} 40^{\prime} 1.2^{\prime \prime} \mathrm{W}\right)$. The soil type is classified as a reading silt loam with a slope between $0 \%$ and $2 \%$. Twenty pioneer sorghum hybrids with different released years were planted in a randomized complete block design at a density of 13 plants $\mathrm{m}^{-2}$. Sorghum genotypes were pioneer hybrids spanning six decades of genetic selection (from 1963 until 2017). Each hybrid was replicated three times for a total of 60 plots. The hybrids were planted on June 8,2019 , in blocks with eight rows $5.3 \mathrm{~m}$ in length, with a row spacing of $0.76 \mathrm{~m}$. Fertility and pest control measures were taken when necessary to ensure plant health throughout the season. Figure 1 shows the layout of the experiment. Both aerial imagery and ground truth data were taken, with aerial imagery corresponding to the flowering (August 9, 2019), soft dough (August 29, 2019), hard dough (September 11, 2019), and physiological maturity (September 26, 2019) stages and ground truth data being taken at flowering, soft dough, and physiological maturity. Ground truth measurements were collected over 2 to 3 days for each growth stage (flowering, August 5, August 9, August 14, 2019; soft dough, August 19, August 22, August 29, 2019; physiological maturity, September 25, October 3, 2019), as sorghum hybrids differed in maturity groups, therefore, reaching each growth stage at slightly different dates. For more information on flights and ground measurements, see Secs. 2.2 and 2.4, respectively.

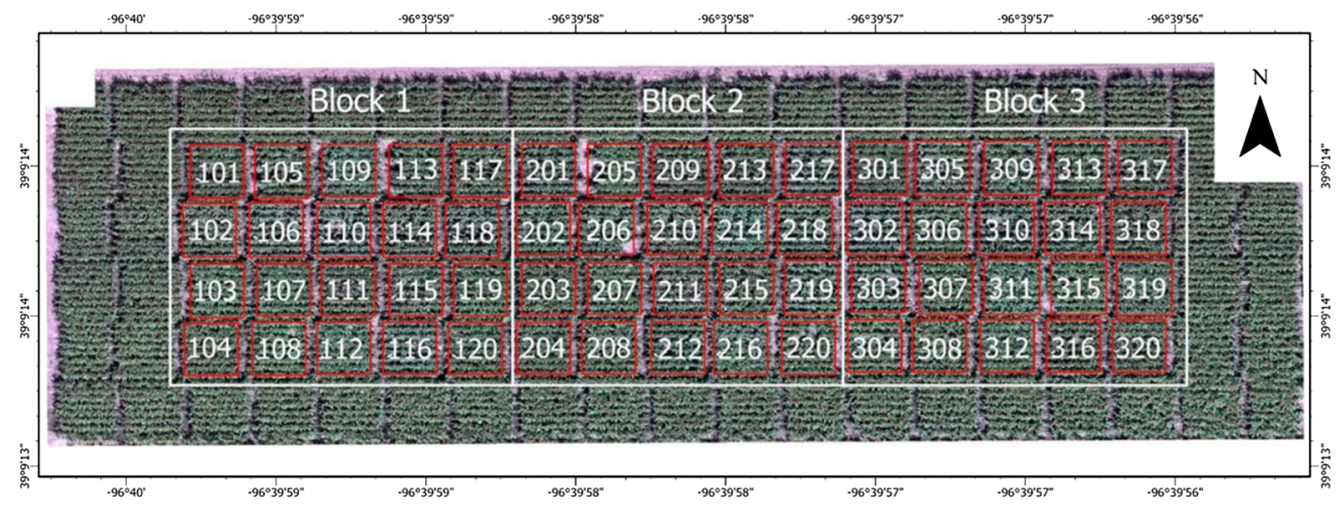

Fig 1 Overview of field study in Manhattan, Kansas. Twenty sorghum genotype plots (indicated by the red boxes) were planted randomly within three blocks, indicated by the white squares. 


\subsection{Data Collection}

Image collection, processing, and data extraction followed a framework presented in Fig. 2. To collect aerial imagery, the UAS used for this study was a DJI Matrice $200^{49}$ outfitted with a MicaSense RedEdge-MX multispectral camera. ${ }^{50}$ The Matrice 200 design includes a DJI SkyPort integration kit, allowing the sensor to be quickly mounted on the camera gimbal. The RedEdge-MX sensor is a five-banded multispectral sensor, able to simultaneously capture five narrow bandwidths on both the visible and invisible electromagnetic spectrum (blue, 465 to $485 \mathrm{~nm}$; green, 550 to $570 \mathrm{~nm}$; red, 663 to $673 \mathrm{~nm}$; RE, 712 to $722 \mathrm{~nm}$; NIR, 820 to $860 \mathrm{~nm}$ ). The camera can capture a spatial resolution of $8 \mathrm{~cm} \mathrm{pixel}^{-1}$ at an altitude of $122 \mathrm{~m}$ and is equipped with a downwelling light sensor to detect changes in ambient lighting conditions during flight.

Prior to flights, ground control points (GCPs) were set around the perimeter of the study, and real time kinematic (RTK) GPS points were taken at each target. Throughout the growing season, four flights were flown in accordance with grain sorghum growth stage, primarily focusing on the reproductive period of the crop: flowering, soft dough, hard dough, and physiological maturity. To ensure lighting conditions were the same for all flights, each mission was flown under clear, sunny conditions within $\pm 2.5 \mathrm{~h}$ of solar noon. Due to close proximity to class $\mathrm{D}$ airspace, flight altitude was limited to $30 \mathrm{~m}$, with a forward and side overlap set to $80 \%$ to ensure clear image orthomosaic production. Missions were planned and uploaded to the aircraft using the DJI Pilot ${ }^{51}$ application, with all missions conducted as GPS waypoint mapping missions.

Image collection

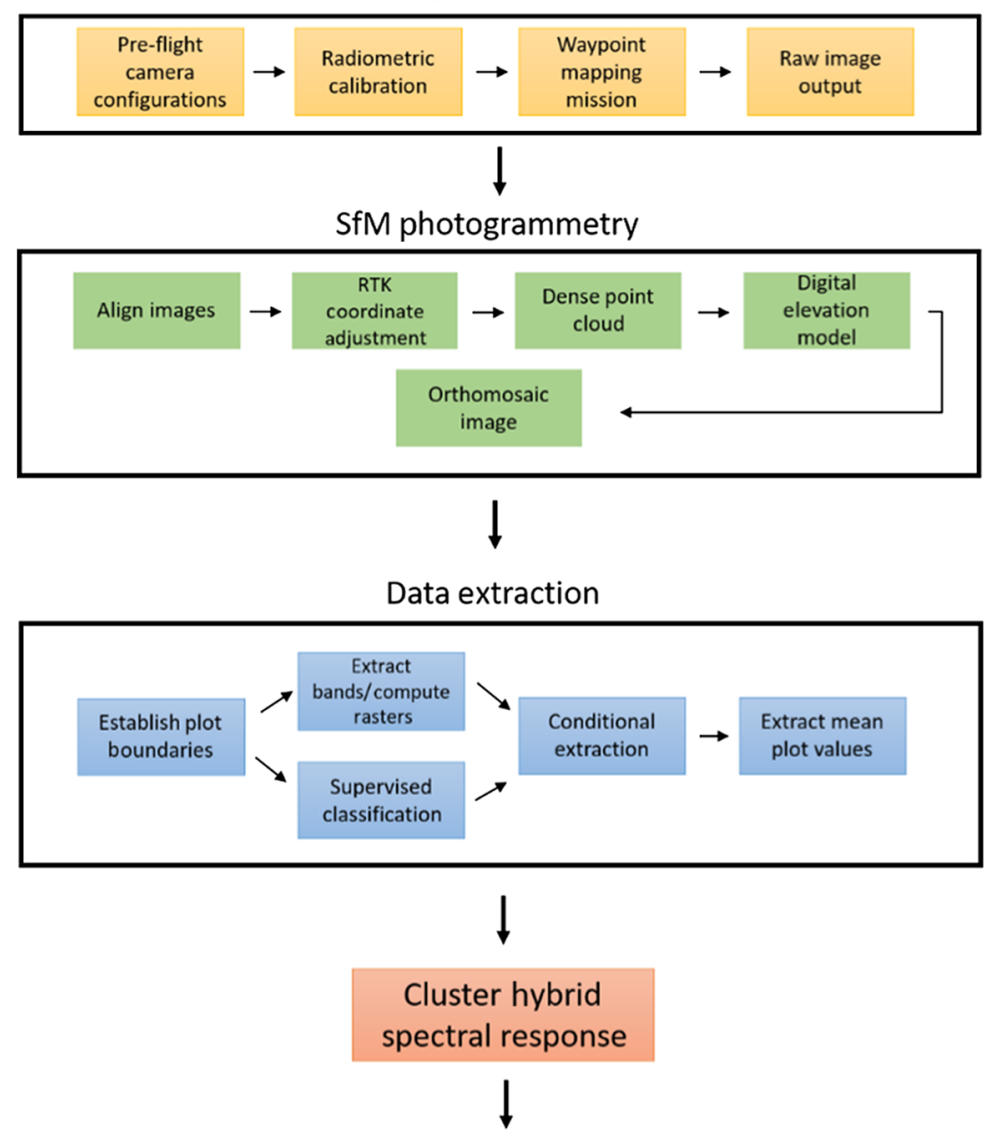

Locate plots of

interest

Fig 2 Workflow diagram of image collection, image processing, data extraction, and statistical analysis. 
Waypoint missions produce flight plan of GPS points with altitude, flight area, and overlap settings factored into it, creating points to which the aircraft will travel to during flight. The RedEdge-MX camera was set to collect imagery every $2 \mathrm{~s}$ to ensure that enough images would be collected for processing. Following recommendations from the manufacturer, gain (ISO) and exposure (i.e., shutter speed and aperture) were left at an automatic setting, allowing for the camera to self-adjust these settings for the conditions of the flights.

To assess image data quality, the signal-to-noise ratio (SNR) was computed. The SNR is an important parameter of remote sensing imagery, determining the quality of imagery that the camera can collect. ${ }^{52}$ The SNR is commonly estimated by computing the mean pixel value to the standard deviation of a homogeneous area. ${ }^{52,53}$ To test this, four Masonite boards with dimensions of $0.61 \mathrm{~m} \times 0.61 \mathrm{~m}$ were painted with a flat white, flat black, flat brown, and Italian Olive color. Each color was chosen to replicate certain homogeneous features that would be found within a sorghum field (white representing maximum reflectance values, black for shadows, brown for soil, and Italian Olive for vegetation). Images of the boards were captured on a sunny day under the same conditions as the flights, and the ratio was computed for each band. After converting each ratio to $\mathrm{dB}$, each band's SNR (over each panel) was averaged to produce an overall SNR, which was found to be $26 \mathrm{~dB}$. Cameras over $20 \mathrm{~dB}$ are considered high-quality research cameras. ${ }^{52,54}$

\subsection{Image Processing}

To process the images, we used structure-from-motion photogrammetry. This technique results in the production of three-dimensional surface models and orthomosaic image generation by processing a series of overlapping images.$^{55}$ The main steps in processing the imagery included image orthorectification, data extraction, and exportation for statistical analysis. Images taken via UAS were saved on an onboard SD card as 16-bit TIFF files and were tagged with GPS coordinates. UAS images were uploaded into Agisoft Metashape (Version 1.5.3, St. Petersburg, Russia) $^{56}$ where images were layered into multispectral images. Radiometric calibration converting digital numbers into reflectance values was conducted using a MicaSense calibration panel. These images were then aligned by matching common features shared between photos, and a series of tie points were then computed into a sparse point cloud. RTK points were then placed onto each GCP to provide ground-reference points for more accurate alignment. A dense point cloud was then computed, followed by a digital elevation model, and finally an orthomosaic photo was produced. The end orthomosaic was produced as an unsigned 16-bit image. ${ }^{57}$ This process was repeated for each flight during this study. Each orthomosaic had a spatial resolution between 2.2 and $2.3 \mathrm{~cm} /$ pixel, and orthomosaics were then exported to ArcGIS Pro (Version 2.5, Redlands, California) $^{58}$ for further analysis.

\subsection{Ground Truth Measurements}

Plant traits specifically related to biomass were chosen to be sampled through a destructive sampling process. These traits include fresh and dry aboveground whole plant biomass at varying growth stages during the reproductive period. Plant fractions were separated in leaves and stem during vegetative stages; and leaves, stem, and panicle (plus grain) during the reproductive stages. In addition, LAI at each sampling stage was measured, along with end-of-season yields.

Fresh biomass samples were taken at the flowering, soft dough, and physiological maturity growth stages, in the third and fourth rows of each plot. At each stage, all above-ground sorghum biomass within a $0.45-\mathrm{m}$ length was sampled. Fresh weight of the samples was recorded, with subsequent partitioning of leaves, stems, and panicles. To determine LAI, three plants were chosen at random from the sampled plants, and each leaf from these plants was measured with a Licor $3100 \mathrm{C}$ leaf area meter. ${ }^{59}$ To obtain dry biomass measurements, all samples were ovendried at $65^{\circ} \mathrm{C}$ until constant weight was achieved. At physiological maturity, rows 6 and 7 were machine harvested for final grain yield. Fresh and dry biomass measurements were adjusted to $\mathrm{g} \mathrm{m}^{-2}$, LAI to leaf area $\mathrm{m}^{-2}$, and grain yield to $\mathrm{kg} \mathrm{ha}^{-1}$.

For senescence, a subsample of five consecutive plants were set aside for ground-truth measurements in each plot. These plants were set aside in the seventh row of each plot. 
Leaf senescence was defined as the decrease in green color due to the breakdown of leaf chloroplasts, ${ }^{60}$ resulting in a certain percentage of leaf greenness loss for any given measurement stage. Each leaf on each plant was scored visually for leaf senescence on a scale of 100 (no visible senescence) to 0 (complete leaf mortality). Measurements were taken at soft dough, hard dough, and physiological maturity and were taken from the first eight leaves of the canopy with the flag leaf being the first leaf measured. To ensure leaf senescence was measured from maximum leaf greenness to maturity, an additional set of ground measurements were taken at $F$, and only leaves that scored 100 at this stage were used for analysis. This proved effective, as nearly all the top eight leaves showed no signs of senescence at this stage.

Prior to flights, elevated ground targets with dimensions of $0.3 \mathrm{~m} \times 0.3 \mathrm{~m}$ were placed between the fifth and sixth rows of each plot indicating the location of the ground-measured plants. Targets were placed exactly one row to the north of the plants to avoid casting shadows that would impede UAS data collection. In all cases, the width of the targets corresponded to the length of the measured plants, allowing for their locations to be identified when extracting data from the imagery.

\subsection{Image Data Analysis}

From the original orthomosaic data, image background noise was then removed via image classification. A supervised, pixel-based classification was chosen to allow the greatest user input to define classes. ${ }^{61}$ Each image was classified into four classes: sorghum leaves, shadows, soil, and grain heads. The only exception to this classification schema was the imagery collected at the $F$ stage, which was classified as leaves, shadows, and soil because grain heads were not yet distinguishable from vegetation. As larger numbers of training samples are expected to increase supervised classification accuracies, ${ }^{62} 20$ representative training sample polygons for each class were collected from each image. ${ }^{61}$ Separate training samples were generated for each orthomosaic to increase classification accuracies. A support vector machine algorithm was chosen for the classification in this case,${ }^{61}$ and a new raster image was created. Accuracy assessments were conducted using a stratified random sampling procedure with 500 total points. Accuracies for sorghum leaf classifications ranged between $88 \%$ and $95 \%$ are correct for any given flight stage, indicating that vegetation was accurately classified when compared with a threshold of $85 \% .{ }^{63}$

After classification, each spectral band was extracted from the original orthomosaic. As outlined by Potgieter et al., ${ }^{36}$ each band was extracted and was normalized between 0 and 1 . To establish plot boundaries, shape-file polygons were drawn around both the whole plots and designated senescence plants, and data were extracted from each region. The average pixel value for each spectral band was extracted, and VIs were computed based on significant findings of spectral bands (see Sec. 3). Each band/VI was extracted with a conditional statement, allowing for only data to be extracted from the "leaves" class to mask data from background features. The data were then exported for statistical analysis.

\subsection{Statistical Analysis}

Statistical analysis was conducted using $R .^{64}$ To analyze spectral band relationships among biomass, yield, and LAI, simple correlation and regression analyses were used. The coefficient of determination $\left(r^{2}\right)$ and root-mean-square error (RMSE) were also determined to verify the performance of the regression models. ${ }^{45}$ For bands that were observed to be consistently significant, VIs were computed that composed of these bands to further investigate the relationships with ground-sampled data. From this data, either spectral bands or VIs were chosen for further analysis based on correlation and regression coefficient values. Hierarchical clustering was then used to cluster the significant spectral data into three distinct groups, based on Euclidean distance between clusters. For each growth stage, the mean NIR band value for each hybrid was hierarchically clustered, and each hybrid was divided into three groups (1 to 3 ). To determine if significant differences existed in ground-sampled traits as defined by each cluster group, a one-way analysis of variance (ANOVA) was conducted using the mean of each cluster, comparing the effect of cluster groups on plant traits. A Tukey honest significant difference test ${ }^{65}$ was used to separate means from each cluster group. 
To analyze senescence patterns, both correlation and simple regression analyses were used to determine the relation of spectral data to senescence scores at each growth stage. Each leaf that was scored for senescence was averaged into a "plant" score, with each plant score was averaged to form a "plot" score. The mean spectral band/VI score was correlated and regressed against the mean plot scores to determine significant relationships. In the same manner, the relationship between spectral data and postflowering senescence rates was determined. Senescence rates were determined by subtracting the mean senescence score at maturity from mean scores at flowering, and spectral change rates were determined in the same manner. ${ }^{38}$ As previously, hierarchical clustering using the $R$ base package was used to divide each hybrid into three groups based on spectral responses, and a one-way ANOVA (comparing the effect of cluster on senescence/senescence rates) and Tukey HSD test conducted to determine significant differences in ground-measured scores. For all analyses, the ANOVAs and mean separations were computed using the "car" ${ }^{\prime 66}$ and "agricolae" ${ }^{\prime 67} R$ packages, respectively. All significance levels were set at $\alpha=0.05$.

\section{Results}

\subsection{Biomass, LAl, and Yield Traits}

A variety of significant and nonsignificant results resulted from the correlation and regression analyses of the five spectral bands and field-measured plant traits (Table 1). Regression and residual plots for selected significantly correlated plant traits and spectral bands are shown in Fig. 3. The NIR band was seen to be the most consistently related to these traits across all growth stages. Weak to moderate relationships were observed between the NIR band and fresh biomass traits ( $r=0.36$ to $0.61 ; r^{2}=0.10$ to 0.37 ; RMSE $=0.01$ to 0.02 ). Most notably, the highest relationships were seen with fresh leaf biomass at each stage $\left(r=0.51\right.$ to $0.61 ; r^{2}=$ 0.26 to 0.37 ). Weak to no significant relationships were observed with dry biomass at flowering, but total, stem, and leaf dry biomass were significantly related to the NIR band at the soft dough and maturity stages ( $r=0.30$ to $0.46 ; r^{2}=0.09$ to 0.21 ). For LAI, weak correlations were observed between the blue and NIR bands at flowering but were not significantly related at any other stage. As the blue band was significantly related to certain fresh and dry biomass traits for flowering and soft dough, these relationships were not statistically advantageous over the NIR band.

Based on these overall results, the blue, green, red, and NIR band was chosen to create VIs to further investigate these relationships. The blue normalized difference vegetation index (BNDVI), green NDVI (GNDVI), NDVI, simple ratio (SR), and enhanced vegetation index (EVI) were all computed (Table 2). Results shown in Table 3 indicate significant relationships between the EVI and fresh biomass traits across all measured growth stages ( $r=0.28$ to 0.50 , $r^{2}=0.08$ to 0.25 , RMSE $=0.02$ to 0.04 ), with the exception of leaf fresh biomass at soft dough. In addition, significant relationships with fresh biomass traits were observed with the GNDVI at flowering $\left(r=0.39, r^{2}=0.15\right.$ to 0.16 , RMSE $\left.=0.01\right)$ and with the SR at $M(r=0.29$ to 0.34 , $r^{2}=0.09$ to 0.11 , RMSE $=0.43$ to 0.44 ). Total, leaf, and stem dry biomass were significant for the EVI $\left(r=0.31\right.$ to $0.39, r^{2}=0.10$ to 0.15 , RMSE $\left.=0.03\right)$ and SR $\left(r=0.30\right.$ to $0.33, r^{2}=$ 0.09 to 0.11 , RMSE $=0.43$ to 0.44 ) at maturity. As a whole, it was determined that the NIR band was more consistently significant with biomass traits than the VIs, so it was selected for further analysis.

The mean ground-sampled trait for each cluster group was then analyzed via ANOVA and separated with the Tukey honest significant difference test for traits found significant in the previous correlation and regression analyses (Table 4). Within the assigned clusters, significant differences were seen with fresh and dry leaf biomass for all growth stages. No comparisons were made with total and stem dry biomass at flowering because it was not significantly related with NIR data at flowering, and no significant differences were seen between groups at soft dough or physiological maturity. For both total and stem fresh biomass, significant differences were only seen between groups at maturity. LAI mean separations at flowering revealed no 
Barnhart et al.: High-resolution unmanned aircraft systems imagery...

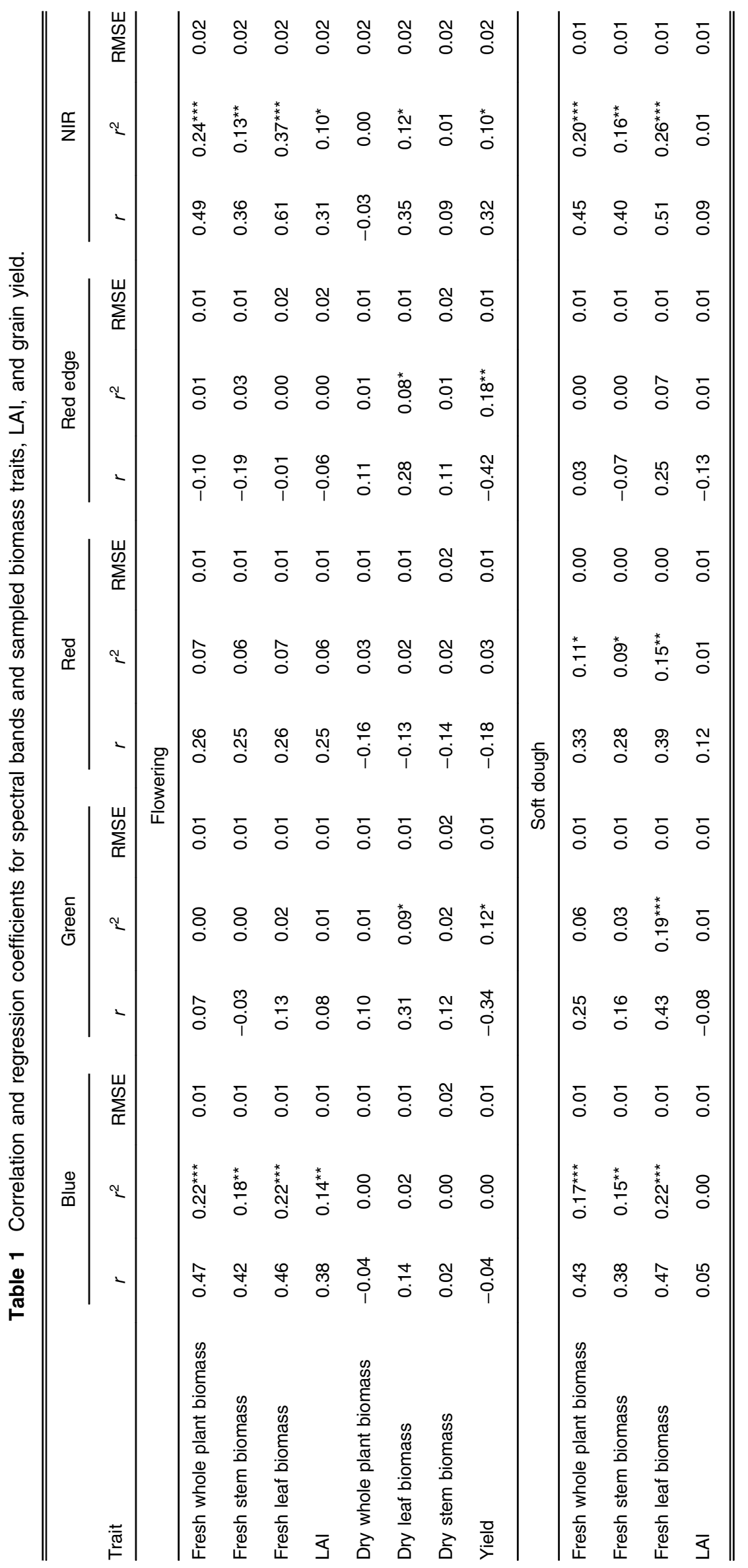


Barnhart et al.: High-resolution unmanned aircraft systems imagery...

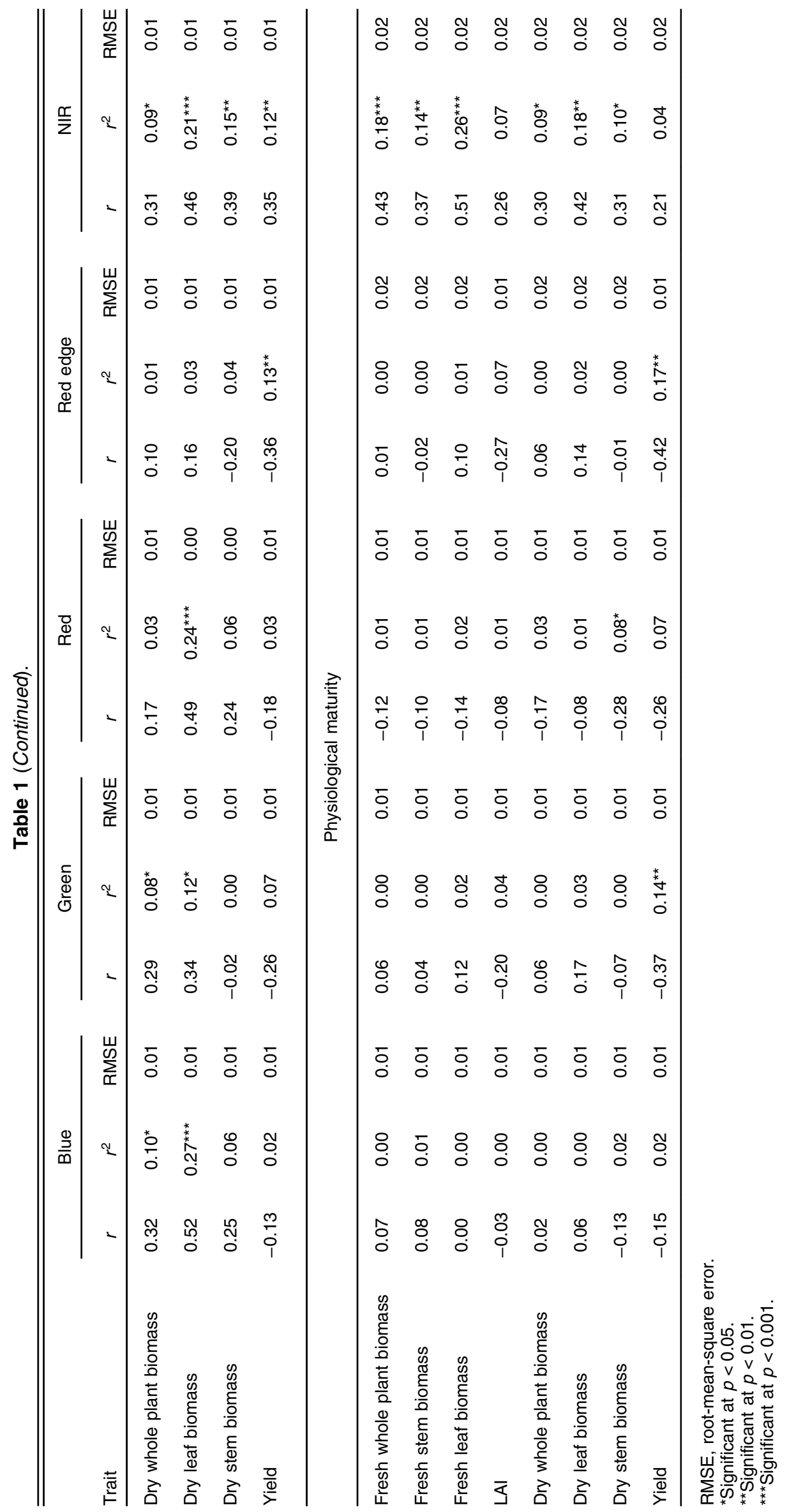



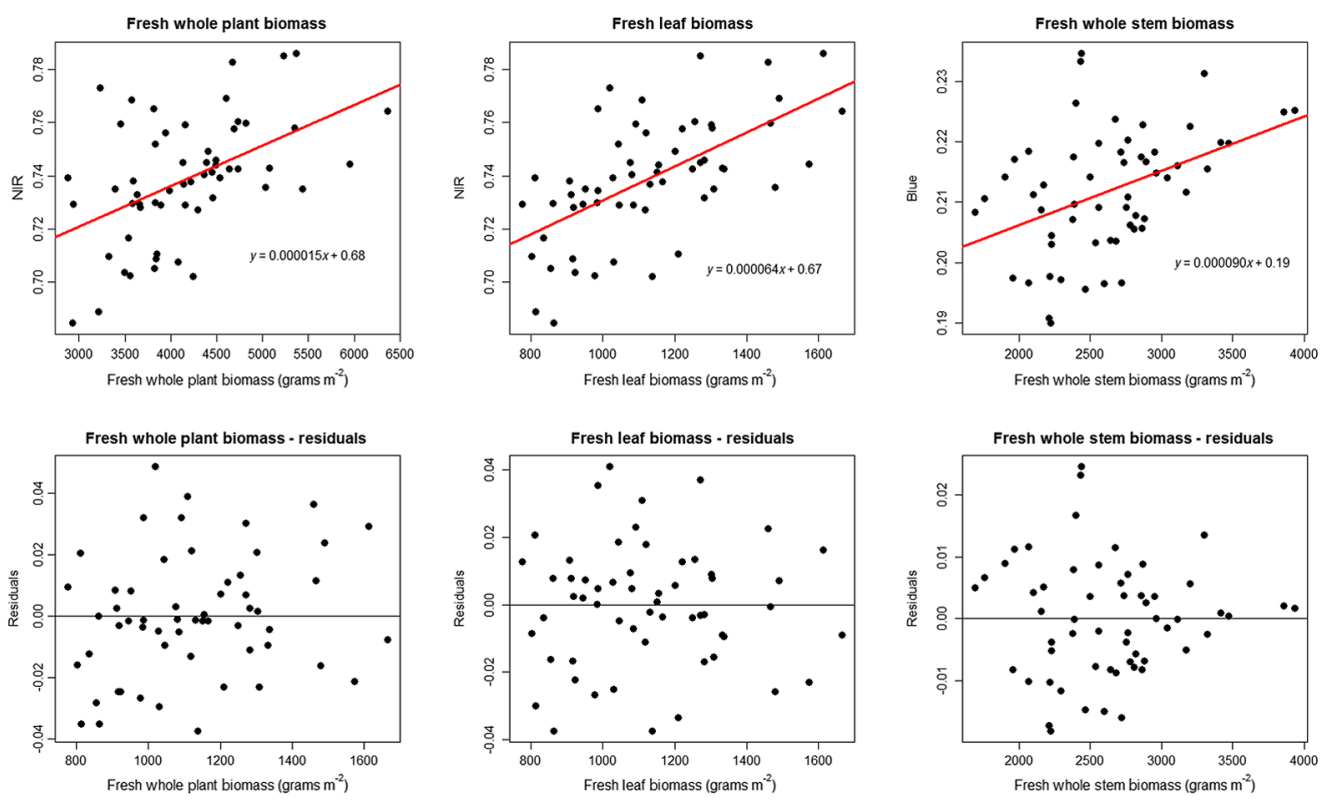

Fig 3 Regression and residual plots for fresh whole plant biomass, fresh leaf biomass, and fresh whole stem biomass as regressed against the NIR, NIR, and blue bands, respectively. Data shown here are taken from the $\mathrm{F}$ growth stage.

Table 2 Vegetation indices computed for biomass, LAI, and yield comparison.

\begin{tabular}{lcc}
\hline \hline Vegetation index & Equations & Reference \\
\hline BNDVI & $\frac{\mathrm{NIR}-\mathrm{B}}{\mathrm{NIR}+\mathrm{B}}$ & 68 \\
GNDVI & $\frac{\mathrm{NIR}-\mathrm{G}}{\mathrm{NIR}+\mathrm{G}}$ & 37,69 \\
NDVI & $\frac{\mathrm{NIR}-\mathrm{R}}{\mathrm{NIR}+\mathrm{R}}$ & 70 \\
SR & $\frac{\mathrm{NIR}}{\mathrm{R}}$ & 71 \\
EVI & $2.5 \times \frac{\mathrm{NIR}-\mathrm{R}}{\mathrm{NIR}+6 \times \mathrm{R}-7.5 \times \mathrm{B}+1}$ & 37,72 \\
\hline \hline
\end{tabular}

BNDVI, blue normalized difference vegetation index; GNDVI, green normalized difference vegetation index; NDVI, normalized difference vegetation index; SR, simple ratio, $\mathrm{EVI}$, enhanced vegetation index.

significant differences, with no further comparisons made due to insignificant relationships with NIR data.

As demonstrated in Table 4, it was discovered that the GNDVI ( $r=0.39$ to $0.56, r^{2}=0.15$ to 0.31 , RMSE $=0.01$ to 0.02$)$ and the SR $\left(0.30\right.$ to $0.56, r^{2}=0.09$ to $0.32, \operatorname{RMSE}=0.44$ to 0.48 ) were the most related to final grain yields throughout the postflowering grow stages. As multispectral data taken at flowering have been found to be the most correlated to final grain yield in previous grain sorghum studies ${ }^{45,73}$ the GNDVI was used for further analysis since it was found to be the most related to yield at flowering in our study $\left(r=0.56, r^{2}=0.31\right.$, RMSE $=0.01$ ). The mean GNDVI scores for each hybrid was clustered and divided into three distinct groups (Fig. 4). Through the ANOVA to determine yield differences, we found no significant differences between clusters $(F=0.001, p=0.97)$. To determine if there were significant differences among yield that the cluster groups may have overlooked, an additional one-way ANOVA was conducted to test the effect of hybrid on yield without clustering. No significant yield differences were found among the hybrids in this study $(F=1.70, p=0.09)$. 
Barnhart et al.: High-resolution unmanned aircraft systems imagery...

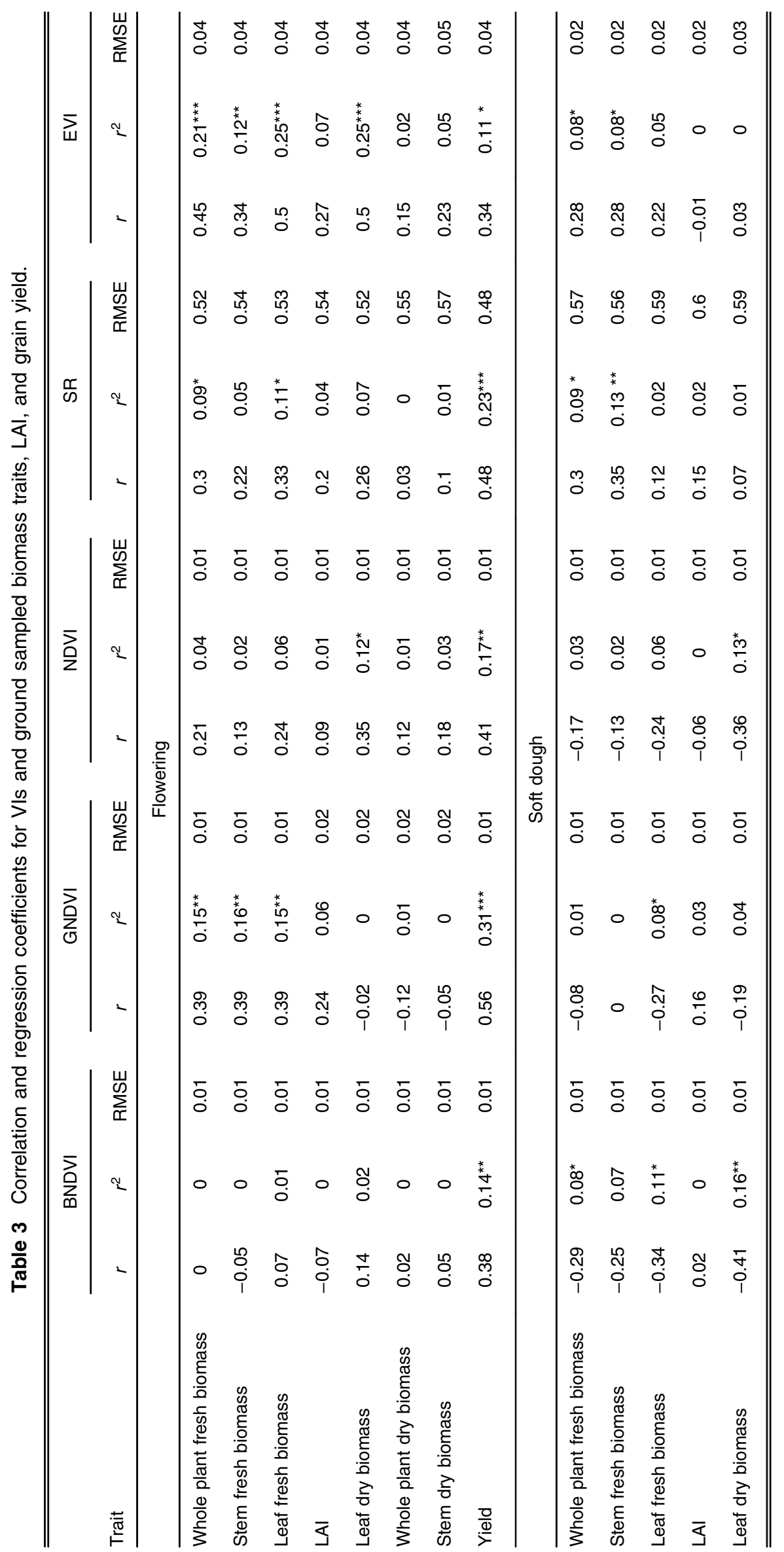


Barnhart et al.: High-resolution unmanned aircraft systems imagery...

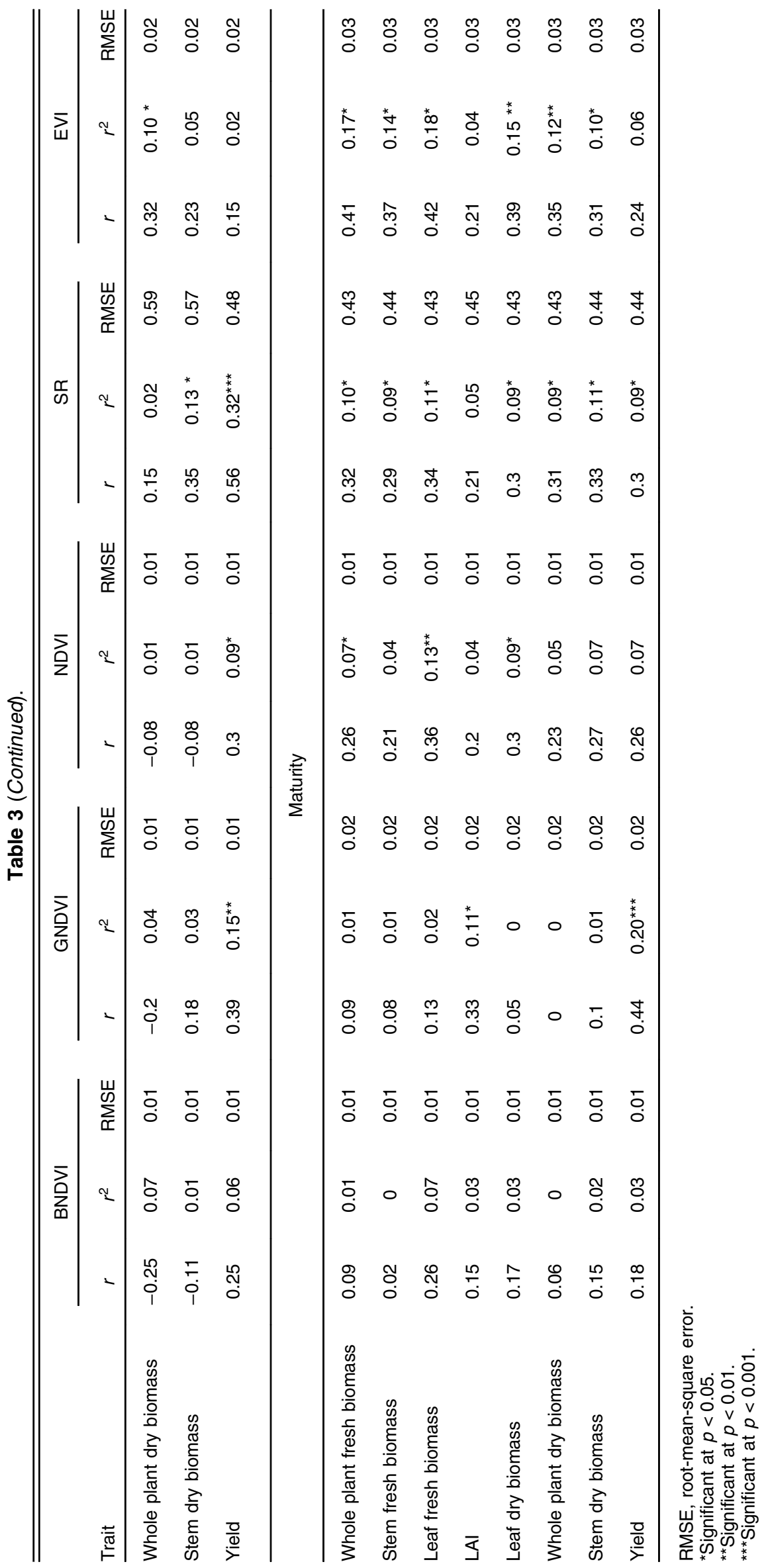


Table 4 Results of ANOVA and Tukey honest significant difference test for significant differences in biomass traits, LAI, and grain yield in clusters defined by hybrid NIR spectral responses.

\begin{tabular}{|c|c|c|c|c|c|c|c|}
\hline Trait & Cluster & $\begin{array}{c}\text { Flowering } \\
\text { mean }^{1,2}\end{array}$ & $\begin{array}{l}\text { Flowering } \\
\mathrm{SEM}^{3}\end{array}$ & $\begin{array}{l}\text { Soft dough } \\
\text { mean }\end{array}$ & $\begin{array}{l}\text { Soft dough } \\
\text { SEM }\end{array}$ & $\begin{array}{l}\text { Maturity } \\
\text { mean }\end{array}$ & $\begin{array}{l}\text { Maturity } \\
\text { SEM }\end{array}$ \\
\hline \multirow{3}{*}{$\begin{array}{l}\text { Total fresh } \\
\text { biomass }\end{array}$} & 1 & $4326^{a}$ & 154 & $4811^{a}$ & 140 & $4874^{a}$ & 169 \\
\hline & 2 & $4184^{a}$ & 160 & $4913^{a}$ & 291 & $4687^{\mathrm{ab}}$ & 184 \\
\hline & 3 & $3775^{a}$ & 126 & $4304^{a}$ & 247 & $3987^{b}$ & 130 \\
\hline \multirow{3}{*}{$\begin{array}{l}\text { Fresh leaf } \\
\text { biomass }\end{array}$} & 1 & $1195^{a}$ & 44 & $1428^{\mathrm{ab}}$ & 45 & $1224^{a}$ & 46 \\
\hline & 2 & $1097^{\mathrm{ab}}$ & 45 & $1565^{\mathrm{a}}$ & 92 & $1151^{a}$ & 49 \\
\hline & 3 & $997^{b}$ & 48 & $1231^{b}$ & 60 & $932^{b}$ & 34 \\
\hline \multirow{3}{*}{$\begin{array}{l}\text { Fresh stem } \\
\text { biomass }\end{array}$} & 1 & $2665^{a}$ & 101 & $3381^{a}$ & 102 & $3703^{a}$ & 148 \\
\hline & 2 & $2653^{a}$ & 106 & $3348^{a}$ & 219 & $3536^{\mathrm{ab}}$ & 139 \\
\hline & 3 & $2476^{a}$ & 109 & $3073^{a}$ & 192 & $3054^{b}$ & 124 \\
\hline \multirow{3}{*}{$\begin{array}{l}\text { Total dry } \\
\text { biomass }\end{array}$} & 1 & $\mathrm{~N} / \mathrm{A}$ & $\mathrm{N} / \mathrm{A}$ & $1863^{a}$ & 65 & $2941^{a}$ & 124 \\
\hline & 2 & $\mathrm{~N} / \mathrm{A}$ & $\mathrm{N} / \mathrm{A}$ & $1797^{a}$ & 154 & $2878^{a}$ & 126 \\
\hline & 3 & $\mathrm{~N} / \mathrm{A}$ & $\mathrm{N} / \mathrm{A}$ & $1612^{a}$ & 111 & $2627^{a}$ & 112 \\
\hline \multirow{3}{*}{$\begin{array}{l}\text { Dry leaf } \\
\text { biomass }\end{array}$} & 1 & $345^{\mathrm{a}}$ & 14 & $397^{a b}$ & 11 & $353^{a}$ & 12 \\
\hline & 2 & $306^{a b}$ & 18 & $347^{a}$ & 37 & $333^{a b}$ & 15 \\
\hline & 3 & $272^{b}$ & 15 & $318^{b}$ & 13 & $291^{\mathrm{b}}$ & 17 \\
\hline \multirow{3}{*}{$\begin{array}{l}\text { Dry stem } \\
\text { biomass }\end{array}$} & 1 & $\mathrm{~N} / \mathrm{A}$ & $\mathrm{N} / \mathrm{A}$ & $763^{a}$ & 53 & $912^{\mathrm{a}}$ & 51 \\
\hline & 2 & $\mathrm{~N} / \mathrm{A}$ & $\mathrm{N} / \mathrm{A}$ & $840^{a}$ & 153 & $870^{\mathrm{a}}$ & 37 \\
\hline & 3 & $\mathrm{~N} / \mathrm{A}$ & $\mathrm{N} / \mathrm{A}$ & $687^{a}$ & 57 & $761^{a}$ & 38 \\
\hline \multirow[t]{3}{*}{ LAI } & 1 & $4.8^{\mathrm{a}}$ & 0.38 & $\mathrm{~N} / \mathrm{A}$ & $\mathrm{N} / \mathrm{A}$ & $\mathrm{N} / \mathrm{A}$ & $\mathrm{N} / \mathrm{A}$ \\
\hline & 2 & $4.0^{\mathrm{a}}$ & 0.37 & $\mathrm{~N} / \mathrm{A}$ & $\mathrm{N} / \mathrm{A}$ & $\mathrm{N} / \mathrm{A}$ & $\mathrm{N} / \mathrm{A}$ \\
\hline & 3 & $3.7^{\mathrm{a}}$ & 0.29 & $\mathrm{~N} / \mathrm{A}$ & $\mathrm{N} / \mathrm{A}$ & $\mathrm{N} / \mathrm{A}$ & $\mathrm{N} / \mathrm{A}$ \\
\hline
\end{tabular}

${ }^{1}$ Units for biomass, LAI, and yield adjusted for $\mathrm{g} \mathrm{m}^{2-1}$, leaf area $\mathrm{m}^{2-1}$, and $\mathrm{kg} \mathrm{ha}^{-1}$, respectively.

${ }^{2}$ Letters denote Tukey HSD mean separation at $p<0.05$ significance level.

${ }^{3}$ Standard error of the mean.

\subsection{Senescence}

During data analysis, it was discovered that the panel we used to calibrate the images was highly reflective. There was a very high level of saturation in the NIR band in the boundaries drawn around the senescence plants, but there was very little saturation in the RGB bands. Therefore, VIs were computed using the RGB bands, including the excess green index (ExG), normalized difference index (NDI), excess green minus excess red index (ExGR), visible atmospherically resistant index (VARI), and the green leaf index (GLI) (Table 5).

When regressing the individual bands, there were no statistical differences observed with ground-truth scores (data not shown). However, significant relationships were discovered when regressing the RGB VIs chosen for this study (Table 6). At maturity, the most significant VIs were the NDI $\left(r=0.57, r^{2}=0.33\right.$, RMSE $\left.=0.03\right)$, VARI $\left(0.60, r^{2}=0.36\right.$, RMSE $\left.=0.05\right)$, and GLI $\left(r=0.48, r^{2}=0.23\right.$, RMSE $\left.=0.03\right)$, with the VARI being selected for further cluster analysis. Dividing the resulting dendrogram into three groups, the ANOVA analysis showed no statistical differences between clusters $(F=0.53, p=0.47)$. Similarly, an ANOVA analysis comparing the effect of hybrid on senescence scores at maturity showed no statistical differences 


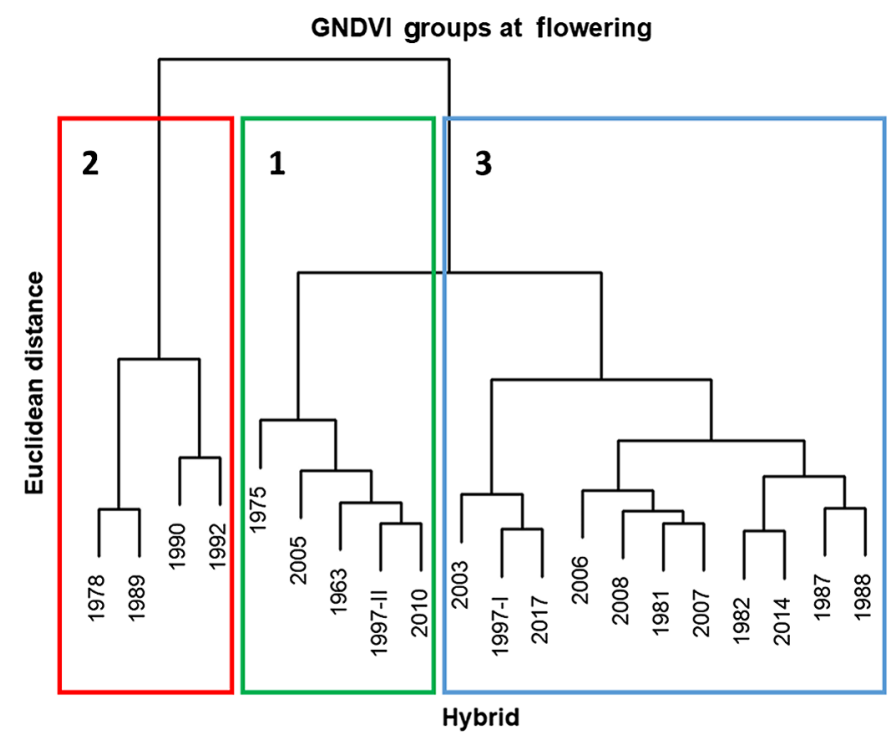

Fig 4 Dendrogram produced by hierarchical clustering the mean GNDVI data for each of the genotypes, resulting in the formation of three distinct cluster groups. Hybrids are denoted by year of release.

Table 5 RGB VIs computed for comparison with groundmeasured senescence scores.

\begin{tabular}{lcc}
\hline \hline Vegetation index & Equations & References \\
\hline ExG & $2 \mathrm{G}-\mathrm{R}-\mathrm{B}$ & 74 to 76 \\
$\mathrm{NDI}$ & $\frac{\mathrm{G}-\mathrm{R}}{\mathrm{G}+\mathrm{R}}$ & 74,76 \\
ExGR & $3 \mathrm{G}-2.4 \mathrm{R}-\mathrm{B}$ & 74 \\
VARI & $\frac{\mathrm{G}-\mathrm{R}}{\mathrm{G}+\mathrm{R}-\mathrm{B}}$ & 77,78 \\
GLI & $\frac{2 \mathrm{G}-\mathrm{R}-\mathrm{B}}{2 \mathrm{G}+\mathrm{R}+\mathrm{B}}$ & 74,79 \\
\hline \hline
\end{tabular}

ExG, excess green; NDI, normalized difference index; ExGR, excess green red; VARI, visible atmospherically resistant index; GLI, green leaf index.

Table 6 Correlation and regression coefficients for RGB VIs and senescence scores.

\begin{tabular}{|c|c|c|c|c|c|c|c|c|c|c|c|c|c|c|c|}
\hline \multirow{2}{*}{$\begin{array}{l}\text { Growth } \\
\text { stage }\end{array}$} & \multicolumn{3}{|c|}{ ExG } & \multicolumn{3}{|c|}{ NDI } & \multicolumn{3}{|c|}{ ExGR } & \multicolumn{3}{|c|}{ VARI } & \multicolumn{3}{|c|}{ GLI } \\
\hline & $r$ & $r^{2}$ & RMSE & $r$ & $r^{2}$ & RMSE & $r$ & $r^{2}$ & RMSE & $r$ & $r^{2}$ & RMSE & $r$ & $r^{2}$ & RMSE \\
\hline SD & 0.31 & $0.10^{*}$ & 0.02 & 0.33 & $0.11^{*}$ & 0.02 & 0.34 & $0.11^{* *}$ & 0.03 & 0.35 & $0.12^{\star *}$ & 0.03 & 0.23 & 0.05 & 0.02 \\
\hline HD & 0.22 & 0.05 & 0.02 & 0.26 & $0.07^{\star}$ & 0.03 & 0.24 & 0.06 & 0.03 & 0.29 & $0.09^{*}$ & 0.04 & 0.21 & 0.04 & 0.02 \\
\hline M & 0.28 & $0.08^{*}$ & 0.03 & 0.57 & $0.33^{\star \star *}$ & 0.03 & 0.35 & $0.12^{\star \star}$ & 0.04 & 0.6 & $0.36^{\star \star \star}$ & 0.05 & 0.48 & $0.23^{\star \star \star}$ & 0.03 \\
\hline
\end{tabular}

ExG, excess green; NDI, normalized difference index; ExGR, excess green red; VARI, visible atmospherically resistant index; GLI, green leaf index; SD, soft dough; HD, hard dough; M, maturity

*Significant at $p<0.05$.

** Significant at $p<0.01$

${ }^{* * *}$ Significant at $p<0.001$. 
among scores at physiological maturity $(F=1.41, p=0.18)$. In the same manner, senescence and VI change rates were analyzed, and the VARI was again found to be the most significantly related to postflowering senescence rates $\left(r=0.42, r^{2}=0.18\right.$, RMSE $\left.=0.05\right)$. ANOVA analysis showed no difference among clusters $(F=0.21, p=0.65)$, and ANOVA analysis comparing the effect of hybrid on senescence rate revealed no significant differences in senescence rates in hybrids used for this study $(F=1.88, p=0.05)$.

\section{Discussion}

To increase crop yields to meet a growing population, breeders must rely on methods to screen crops quickly and thoroughly for desired traits of interest. ${ }^{80}$ In this paper, we have introduced a methodology for sorghum researchers to follow to collect, process, extract, and analyze multispectral data for more efficient screening of large-scale grain sorghum breeding plots for traits associated with SG. As UAS have become a more cost-effective method of obtaining very high spatial resolution imagery for such evaluations, ${ }^{81}$ there is a need for specific methodologies to be developed for sorghum breeders to use this technology for rapid identification of the SG trait. If breeders are able to screen thousands of breeding lines quickly and effectively for this trait, improvements to current grain sorghum hybrids needed to sustain future demands can potentially be made in a much shorter period of time.

When compared with non-SG grain sorghum lines, SG sorghum lines have been related to increased yield and biomass production under heat and water stress. ${ }^{82}$ In our methodology, we were able to find significant differences in fresh and dry biomass traits among cluster groups, as defined by the NIR band. While RGB and NIR data are most frequently combined to produce VIs, the NIR band has been already reported to be significantly correlated with above-ground sorghum biomass. ${ }^{83}$ In this study, clear differences between fresh and dry leaf biomass cluster groups were observed for each measurement date, a result that was not surprising given that sorghum leaves were highly visible to the camera. Because the hybrids used in this study were not specifically chosen due to known differences in biomass traits, further research is needed to validate this methodology for robustness in determining differences in each trait measured for this study. In addition, VI correlation and regression coefficients in this study were much lower than what has been previously reported for sorghum fresh biomass, ${ }^{83,84} \mathrm{LAI},{ }^{45}$ and dry biomass. $^{84}$

Our results demonstrated that at flowering, yield was best predicted with the GNDVI. As the GNDVI has been shown to be a strong predictor of crop yield in previous works, ${ }^{37,85-88}$ these results were not surprising. The GNDVI has been shown to be sensitive to plant chlorophyll concentrations, ${ }^{89,90}$ which has been found to be directly related to end-of-season grain yields. ${ }^{91,92}$ Previous studies have found that spectral data taken at flowering have produced the highest correlations with sorghum final grain yield, ${ }^{45,73}$ which is why we chose to determine clusters with spectral data from this growth stage. Despite a trend of historical yield improvement for the hybrids used in this study, ${ }^{93}$ hybrids in this study were not selected specifically for yield differences. Therefore, further work should be conducted among hybrids with known yield differences to determine if clusters are able to detect significant differences.

In terms of quantifying senescence and senescence rates, our results indicate that RGB imagery alone may be useful in quantifying and characterizing grain sorghum senescence at maturity. In many cases, UAV RGB imagery may be desired over multispectral sensors due to their comparably lower costs. ${ }^{94}$ In terms of evaluating for the SG trait, grain sorghum greenness at PM has been labeled as a very good indicator of SG and has been successfully used to select for drought tolerance in previous sorghum breeding trials. ${ }^{31,95}$ In our study, the highest linear relationships between RGB VI data and senescence scores were observed at maturity. As sorghum plants do not typically completely senesce unless terminated by external factors such as freezing temperatures,${ }^{96}$ senescence patterns are considerably less pronounced when compared with annual crops such as corn and soybeans. This is probably the main reason why sorghum senescence was not well detected at soft dough and hard dough stages in our study. Many studies have previously used VIs such as the normalized difference red edge (NDRE) index to evaluate crop senescence rates by evaluating the spectral differences from flowering to maturity. ${ }^{36,38,97}$ 
Although we did observe the VARI to be significantly related to postflowering senescence rates, we did not observe significant differences in hybrid senescence rates. As none of the hybrids in this study have not been previously observed to have differing senescence rates, further work should be investigated to determine if significant differences in both senescence scores by growth stage and postflowering senescence rates can be differentiated using this methodology.

In situations where very dense vegetation canopies are present, it can be difficult to get accurate VI data with the NIR band. This is because of a well-documented phenomenon involving the "leveling off" or saturation of reflected NIR in dense vegetative canopies, ${ }^{78,98}$ making it difficult to detect changes in plant chlorophyll in these scenarios. In canopies with percent vegetation fractions $>50 \%$, the NDI and VARI have been shown to be more linearly related to vegetation than indices using NIR reflectance. ${ }^{77}$ In sorghum breeding trials with very dense canopies, the NDI or VARI could be useful in detecting rates of senescence at physiological maturity. In environments with limited precipitation, canopy sizes are usually smaller and saturation is not perceived as a problem. ${ }^{99}$ As the SG trait is generally assessed in these environments, further research is needed to evaluate senescence detection for these VIs under such conditions.

The likely explanation for our low correlation and regression coefficients with biomass, LAI, and yield can be traced back to the problems we experienced with the calibration panel. As the panel was highly reflective, most of our NIR data were highly saturated, depending on the flight date. This issue also prevented us from investigating VIs that have been previously related to senescence (i.e., NDRE). We anticipate that stronger relationships could be detected in future research if proper calibration equipment is used for radiometric calibration. In addition, as one of the specific goals for this study was to develop a methodology that could be used by SG breeders, we focused on this and did not have any hybrids that were known to have the SG trait. To use UAV imagery effectively in large-scale sorghum breeding trials, the ability to distinguish between senescence rates of SG and non-SG plots is very important. Further research should be conducted to evaluate this methodology's ability to distinguish differences in sorghum hybrids based on the known presence or absence of the SG trait. Key to analyzing all traits in this study is the use of hierarchical clustering to select hybrids of interest. In breeding trials with thousands of hybrid plots, a cluster analysis can be used to group hybrids with spectral similarities, allowing for hybrids of interest to be investigated with ground-truth evaluation. In theory, this would eliminate the need to investigate every plot, which has the potential to save time, money, labor, and other resources. If subjected to further testing, this methodology shows potential for greatly assisting sorghum breeders looking for traits associated with SG.

Within this study, there are some limitations that should be discussed. First, in terms of the senescence patterns, there were minor variations observed in the field among senescence patterns in the hybrids used for this study. As demonstrated by Potgieter et al., ${ }^{36}$ sorghum lines with different rates of SG-induced senescence should be more easily evaluated for screening SG senescence. As SG delays in senescence are best observed under drought stress, ${ }^{9,95}$ it is possible that SG senescence patterns were unable to be observed due to plentiful rainfall in the 2019 growing season. Future studies using this methodology should be done in precipitation-limited conditions to obtain maximum SG expression. This can be done in controlled environments such as using rain shelters to simulate these conditions. More studies in more locations are necessary to further investigate this methodology for SG evaluation.

To collect visual senescence scores, the top eight leaves of the canopy were estimated based on percentage of senescence, and the average of these scores was used to compare with extracted spectral data. A different method to calculate leaf senescence should be evaluated with the data collected from this study. In addition, the UAS depth of detection into the sorghum canopy remains to be studied. As each leaf was measured, it remains possible to perform a sensitivity analysis to determine if leaves closer to the top of the canopy would result in significant relationships with spectral data.

Due to the highly reflective panel used for radiometric calibration, a high saturation of our data was observed. Because of this saturation, we were unable to obtain highly significant relationships between NIR-based VIs and ground-measured plant traits. Future corrections on this methodology should involve the use of a less-reflective calibration panel, which would help to prevent said saturation. 


\section{Conclusions}

We present a methodology to improve grain sorghum characterization in regard to biomass, yield, and senescence characterization using a consumer-available UAS camera. Results in this study show potential that through hierarchical clustering of sorghum spectral responses, it is possible to group hybrids with significant differences in various measured traits. The NIR band was found significantly related to various biomass traits, including fresh/dry total biomass and leaf biomass. For senescence evaluation, the VARI was observed to have the strongest relation with senescence scores at physiological maturity, as well as postflowering senescence changes. As this methodology has led to the extraction of significant spectral relationships with biomass, grain yield, and senescence scores, we anticipate that with further evaluation, this methodology could greatly assist sorghum breeders in locating genotypes of interest in large-scale sorghum SG breeding trials.

\section{References}

1. K. P. Vos-Fels et al., "Q\&A: modern crop breeding for future food security," BMC Biol. 17, 18 (2019).

2. O. A. Ortez-Amador, "Study of nitrogen limitation and seed nitrogen sources for historical and modern genotypes in soybean," M.Sc. Thesis, Kansas State University, Manhattan, Kansas, United States (2018).

3. H. Li et al., "Fast-forwarding genetic gain," Trends Plant Sci. 23(3), 184-186 (2018).

4. A. J. Challinor et al., "A meta-analysis of crop yield under climate change and adaptation," Nat. Clim. Change 4, 287-291 (2014).

5. A. E. Hall and L. H. Ziska, "Crop breeding strategies for the 21 st century," in Climate Change and Global Crop Productivity, K. R. Reddy and H. F. Hodges, Eds., 1st ed., pp. 407-423, CABI Publishing, New York (2000).

6. A. Stefoska-Needham et al., "Sorghum: an underutilized cereal whole grain with the potential to assist in the prevention of chronic disease," Food Rev. Int. 31(4), 401-437 (2015)

7. K. Harris et al., "Sorghum stay-green QTL individually reduce post-flowering droughtinduced leaf senescence," J. Exp. Bot. 58(2), 327-338 (2007).

8. B. Kassahun et al., "Stay-green expression in early generation sorghum [Sorghum bicolor (L.) Moench] QTL introgression lines," Euphytica 172, 351-362 (2010).

9. D. R. Jordan et al., "The relationship between the stay-green trait and grain yield in elite sorghum hybrids grown in a range of environments," Crop Sci. 52(3), 1153-1161 (2012).

10. M. F. Turner et al., "Non-targeted metabolomics in diverse sorghum breeding lines indicates primary and secondary metabolite profiles are associated with plant biomass accumulation and photosynthesis," Front. Plant Sci. 7, 953-969 (2016).

11. H. Thomas and C. J. Howarth, "Five ways to stay green," J. Exp. Bot. 51(1), 329-337 (2000).

12. P. Ongom, "Association mapping of gene regions for drought tolerance and agronomic traits in sorghum," Ph.D. Dissertation, Purdue University, West Lafayette, Indiana, United States, (2015).

13. A. C. Sanchez et al., "Mapping QTLs associated with drought resistance in sorghum (Sorghum bicolor L. Moench)," Plant Mol. Biol. 48, 713-726 (2002).

14. S. Staggenborg et al., "Grain sorghum and corn comparisons: yield, economic, and environmental responses," Agron. J. 100(6), 1600-1604 (2008).

15. C. W. Mundia et al., "A regional comparison of factors affecting global sorghum production: the case of North America, Asia and Africa's Sahel," Sustainability 11(7), 2135-2152 (2019).

16. T. F. Teferra and J. M. Awika, "Sorghum as a healthy global food security crop: opportunities and challenges," Cereal Food. World 64(5) (2019).

17. Joint FAO/IAEA Programme; Nuclear Techniques in Food and Agriculture, "Sorghum mutation breeding for improving tolerance to abiotic stresses brought about by climate change," http://www-naweb.iaea.org/nafa/news/pbg-sorghum-mutation.html (accessed 2 July 2020). 
18. Digest Project, "Breeding sorghum for improved resistance to biotic and abiotic stresses and enhanced end," http://crsps.net/resource/breeding-sorghum-for-improved-resistanceto-biotic-and-abiotic-stresses-and-enhanced-end-use-characteristics-for-southern-africa/ (accessed 2 July 2020).

19. D. T. Rosenow et al., "Drought tolerant sorghum and cotton germplasm," Agric. Water Manage. 7(1-3), 207-222 (1983).

20. D. T. Rosenow, "Breeding sorghum for drought resistance," in Food Grain Production in Semi Arid Africa, J. M. Menyoga, T. Bezuneh, and A. Youdeowei, Eds., pp. 83-89, OAUSTRC/SAFGRAD, Ouagadougou, Burkina Faso (1987).

21. C. C. Evangelista and N. G. Tangonan, "Reaction of 31 non-senescent sorghum genotypes to stalk rot complex in southern Philippines," Trop. Pest Manage. 36(3), 214-215 (1990).

22. P. K. Subudhi et al., "Quantitative trait loci for the stay green trait in sorghum (Sorghum bicolor L. Moench): consistency across genetic backgrounds and environments," Theor. Appl. Genet. 101, 733-741 (2000).

23. A. K. Joshi et al., "Stay green trait: variation, inheritance and its association with spot blotch resistant in spring wheat (Triticum aestivum L.)," Euphytica 153, 59-71 (2007).

24. Y. Z. Tao et al., "Identification of genomic regions associated with stay green in sorghum by testing RILs in multiple environments," Theor. Appl. Genet. 100, 1225-1232 (2000).

25. H. Thomas and H. Ougham, "The stay-green trait," J. Exp. Bot. 65(14), 3889-3900 (2014).

26. J. C. Clifton-Brown et al., "Comparative responses to water stress in stay-green, rapid- and slow senescing genotypes of the biomass crop, Miscanthus," New Phytol. 154(2), 335-345 (2002).

27. D. N. Duvick, J. S. C. Smith, and M. Cooper, "Long-term selection in a commercial hybrid maize breeding program," in Plant Breeding Reviews Part 2: Long-Term Selection: Crops, Animals, and Bacteria, J. Janick Ed., pp. 109-149, John Wiley \& Sons, Inc. (2004).

28. M. D. Edgerton, "Increasing crop productivity to meet global needs for feed, food, and fuel," Plant Physiol. 149(1), 7-13 (2009).

29. N. Shakoor et al., "High throughput phenotyping to accelerate crop breeding and monitoring of diseases in the field," Curr. Opin. Plant Biol. 38, 184-192 (2017).

30. M. Bogard et al., "Anthesis date mainly explained correlations between post-anthesis leaf senescence, grain yield, and grain protein concentration in a winter wheat population segregating for flowering time QTLs," J. Exp. Bot. 62(10), 3621-3636 (2011).

31. M. K. Wanous et al., "Evaluation of visual rating scales for green leaf retention in sorghum," Crop Sci. 31(6), 1691-1694 (1991).

32. J. L. Araus and J. E. Cairns, "Field high-throughput phenotyping: the new crop breeding frontier," Trends Plant Sci. 19(1), 52-61 (2014).

33. M. F. Buitrago et al., "Connecting infrared spectra with plant traits to identify species," ISPRS J. Photogramm. 139, 183-200 (2018).

34. D. Lu, "The potential and challenge of remote sensing-based biomass estimation," Int. J. Remote Sens. 27(7), 1297-1328 (2006).

35. S. Garrigues et al., "Validation and intercomparison of global leaf area index products derived from remote sensing data," J. Geophys. Res. 113(G2), G02028 (2008).

36. A. B. Potgieter et al., "Unmanned aerial vehicle enables the assessment of seasonal leaf area dynamics of sorghum breeding lines," Front. Plant Sci. 8, 1532 (2017).

37. J. F. Shanahan et al., "Use of remote sensing imagery to estimate corn grain yield," Agron. J. 93(3), 583-589 (2001).

38. M. A. Hassan et al., "Time-series multispectral indices from unmanned aerial vehicle reveal senescence rate in bread wheat," Remote Sens. 10(6), 809 (2018).

39. C. M. Di Bella et al., "Effect of senescent leaves on NDVI-based estimates of fAPAR: Experimental and modelling evidences," Int. J. Remote Sens. 25(23), 5415-5427 (2004).

40. J. P. Curran, "Multispectral remote sensing for the estimation of green leaf area index," Phil. Trans. R. Soc. Lond. A. 309(1508), 257-270 (1983).

41. A. Gitelson and M. N. Merzlyak, "Spectral reflectance changes associated with autumn senescence of Aesculus hippocastanum L. and Acer platanoides L. leaves. Spectral features and relation to chlorophyll estimation," J. Plant Physiol. 143(3), 286-292 (1994). 
42. M. J. Belanger et al., "Comparative relationships between some red edge parameters and seasonal leaf chlorophyll concentrations," Can. J. Remote Sens. 21(1), 16-21 (1995).

43. M. Boyer et al., "Senescence and spectral reflectance in leaves of northern pin oak (Quercus palustris Muenchh.)," Remote Sens. Environ. 25(1), 71-87 (1988).

44. C. Stanton et al., "Unmanned aircraft system-derived crop height and normalized difference vegetation index metrics for sorghum yield and aphid stress assessment," J. Appl. Remote Sens. 11(2), 026035 (2017).

45. S. Shafian et al., "Unmanned aerial systems-based remote sensing for monitoring sorghum growth and development," PLoS One 13, e0196605 (2018).

46. C. Zhang and J. M. Kovacs, "The application of small unmanned aerial systems for precision agriculture: a review," Precis. Agric. 13, 693-712 (2012).

47. N. A. Pugh et al., "Temporal estimates of crop growth in sorghum and maize breeding enabled by unmanned aerial systems," Plant Phenom. J. 1(1), 1-10.

48. "Corteva Agriscience," https://www.corteva.com (Accessed 8 March 2021).

49. DJI, "Matrice 200 series," https://www.dji.com/matrice-200-series (Accessed 8 March 2021).

50. "Micasense RedEdge-MX," https://micasense.com/rededge-mx/ (Accessed 8 March 2021).

51. DJI, Pilot, https://www.dji.com/downloads/djiapp/dji-pilot (Accessed 8 March 2021).

52. B. Lu and Y. He, "Species classification using unmanned aerial vehicle (UAV)-acquired high spatial resolution imagery in a heterogeneous grassland," ISPRS J. Photogramm. 128, 73-85 (2017).

53. R. Hruska et al., "Radiometric and geometric analysis of hyperspectral imagery acquired from an unmanned aerial vehicle," Remote Sens. 4(9), 2736-2752 (2012).

54. D. H. Johnson, "Signal-to-noise ratio," Scholarpedia 1(12), 2088 (2008).

55. M. J. Westoby et al., "'Structure-from-motion' photogrammetry: a low-cost, effective tool for geoscience applications," Geomorphology 179, 300-314 (2012).

56. "Agisoft metashape," https://www.agisoft.com/ (Accessed 8 March 2021).

57. MicaSense, "Overview of histograms and how they are used in Atlas," https://support .micasense.com/hc/en-us/articles/224896827-Overview-of-histograms-and-how-they-areused-in-Atlas (accessed 9 April 2020).

58. ESRI, "ArcGIS Pro," https://www.esri.com/en-us/arcgis/products/arcgis-pro/resources (Accessed 8 March 2021).

59. “LI-3100C area meter," https://www.licor.com/env/products/leaf_area/LI-3100C/ (Accessed 8 March 2021).

60. P. O. Lim et al., "Leaf senescence," Annu. Rev. Plant Biol. 58, 115-136 (2007).

61. I. Barnhart et al., "Use of high-resolution unmanned aerial systems imagery and machine learning to evaluate grain sorghum tolerance to mesotrione," J. Appl. Remote Sens. 15(1), 014516 (2021).

62. K. Perumal and R. Bhaskaran, "SVM-based effective land use classification system for multispectral remote sensing images," IJCSIS 6, 95-107 (2009)

63. G. M. Foody, "SVM-based effective land use classification system for multispectral remote sensing images," Int. J. Remote Sens. 26(5), 1217-1228 (2005).

64. R Core Team, R: A Language and Environment for Statistical Computing, R Foundation for Statistical Computing, Vienna (2020).

65. W. Haynes, "Tukey's test," in Encyclopedia of Systems Biology, W. Dubitzky et al., Eds., Springer, New York (2013).

66. J. Fox and S. Weisberg, $A n\{R\}$ Companion to Applied Regression, 3rd ed., Sage, Thousand Oaks, California (2019).

67. R program, "Agricolae: statistical procedures for agricultural research," https://cran.r-project .org/web/packages/agricolae/index.html (Accessed 10 July 2020).

68. D. Van der Merwe and K. P. Price, "Harmful algal bloom characterization at ultra-high spatial and temporal resolution using small unmanned aircraft systems," Toxins 7(4), 1065-1078 (2015).

69. M. Basso et al., "Proposal for an embedded system architecture using a GNDVI algorithm to support UAV-based agrochemical spraying," Sensors 19(24), 5397 (2019). 
70. J. Rouse et al., "Monitoring vegetation systems in the great plains with ERTS," in Third Earth Resour. Technol. Satell.-1 Symp., Volume 1: Tech. Present. Sect. A, S. C. Freden, E. P. Mercanti, and M. A. Becker, Eds., pp. 309-317, NASA (1974).

71. P. Sternberg et al., "Reduced simple ratio better than NDVI for estimating LAI in Finnish pine and spruce stands," Silva Fenn. 38(1), 3-14 (2004).

72. S. M. Ali and S. S. Salman, "Estimating the yield of rice farms in southern Iraq using Landsat images," Int. J. Sci. Eng. Res. 6(8), 1607-1614 (2015).

73. C. Yang and J. H. Everitt, "Relationships between yield monitor data and airborne multidate multispectral digital imagery for grain sorghum," Precis. Agric. 3, 373-388 (2002).

74. B. Zhao et al., "Rapeseed seedling stand counting and seeding performance evaluation at two early growth stages based on unmanned aerial vehicle imagery," Front. Plant Sci. 9, 1362 (2018).

75. D. M. Woebbecke et al., "Color indices for weed identification under various soil, residue, and lighting conditions," Trans. ASAE 38(1), 259-269 (1995).

76. G. E. Meyer and J. C. Neto, "Verification of color vegetation indices for automated crop imaging applications," Comput. Electron. Agric. 63(2), 282-293 (2008).

77. A. A. Gitelson et al., "Novel algorithms for remote estimation of vegetation fraction," Remote Sens. Environ. 80(1), 76-87 (2002).

78. J. Zhang et al., "Applications of unmanned aerial vehicle based imagery in turfgrass field trials," Front. Plant Sci. 10, 279 (2019).

79. M. Louhaichi et al., "Spatially located platform and aerial photography for documentation of grazing impacts on wheat," Geocarto Int. 16(1), 65-70 (2001).

80. A. Hassanzadeh et al., "Yield modeling of snap bean based on hyperspectral sensing: a greenhouse study," J. Appl. Remote Sens. 14(2), 024519 (2020).

81. F. H. Holman et al., "High throughput field phenotyping of wheat plant height and growth rate in field plot trials using UAV based remote sensing," Remote Sens. 8(12), 1031 (2016).

82. A. K. Borrell et al., "Does maintaining green leaf area in sorghum improve yield under drought? II. Dry matter production and yield," Crop Sci. 40(4), 1037-1048 (2000).

83. R. Sui et al., "High-biomass sorghum yield estimate with aerial imagery," J. Appl. Remote Sens. 5(1), 053523 (2011).

84. J. Li et al., "Elucidating sorghum biomass, nitrogen and chlorophyll contents with spectral and morphological traits derived from unmanned aircraft system," Front. Plant Sci. 9, 1406 (2018).

85. M. M. Rahman and A. J. Robson, "A novel approach for sugarcane yield prediction using landsat time series imagery: a case study on Bundaberg region," Adv. Remote Sens. 5(2), 93-102 (2016).

86. S. Pradhan et al., "Canopy reflectance spectra of wheat as related to crop yield, grain protein under different management practices," J. Agrometeorol. 14(1), 21-25 (2012)

87. C. Yang et al., "Using multispectral imagery and linear spectral unmixing techniques for estimating crop yield variability," Trans. ASABE 50(2), 6676-674 (2007).

88. S. M. Moges et al., "Evaluation of green, red, and near infrared bands for predicting winter wheat biomass, nitrogen uptake, and final grain yield," J. Plant Nutr. 27(8), 1431-1441 (2005).

89. A. Kayad, et al., "Monitoring within-field variability of corn yield using sentinel-2 and machine learning techniques," Remote Sens. 11(23), 2873 (2019).

90. A. A. Gitelson et al., "Use of a green channel in remote sensing of global vegetation from EOS-MODIS," Remote Sens. Environ. 58(3), 289-298 (1996).

91. K. Ramesh et al., "Chlorophyll dynamics in rice (Oryza sativa) before and after flowering based on SPAD (chlorophyll) meter monitoring and its relation with grain yield," J. Agron. Crop Sci. 188(2), 102-105 (2002).

92. M. A. Gonçalves da Silva et al., "Monitoring and evaluation of need for nitrogen fertilizer topdressing for maize leaf chlorophyll readings and the relationship with grain yield," Braz. Arch. Biol. Technol. 54(4), 665-674 (2011).

93. P. A. Demarco et al., "Physiological changes across historical sorghum hybrids released during the last six decades," Kansas Agr. Exp. St. Res. Rep. 6(15), 1-6 (2020). 
94. R. Makanza et al., "High-throughput phenotyping of canopy cover and senescence in maize field trials using aerial digital canopy imaging," Remote Sens. 10(2), 330 (2018).

95. A. K. Borrell et al., "Does maintaining green leaf area in sorghum improve yield under drought? I. Leaf growth and senescence," Crop Sci. 40(4), 1026-1037 (2000).

96. D. Regehr, "Preharvest desiccants for sorghum," in Grain Sorghum Production Handbook, pp. 23-24, Kansas State University Agricultural Experiment Station and Cooperative Extension Service, Manhattan, Kansas (1998).

97. A. B. Potgieter, et al., "Determining crop growth dynamics in sorghum breeding trials through remote and proximal sensing technologies," in Proc. IGARSS 2018-2018 IEEE Int. Geosci. and Remote Sens. Symp., Valencia, pp. 8244-8247 (2018).

98. A. A. Gitelson, "Wide dynamic range vegetation index for remote quantification of biophysical characteristics of vegetation," J. Plant Physiol. 161(2), 165-173 (2004).

99. G. Montazeaud et al., "Predicting wheat maturity and stay-green parameters by modeling spectral reflectance measurements and their contribution to grain yield under rainfed conditions," Field Crop. Res. 196, 191-198 (2016).

Isaac Barnhart received his MS degree from Kansas State University in agronomy, focusing on using unmanned aerial vehicles for cultivar selection in grain sorghum breeding trials. He is currently continuing as a $\mathrm{PhD}$ student in agronomy (weed science) at Kansas State, focusing on using deep learning object detection algorithms for weed detection in cropping systems.

Paula Demarco received her BS degree from the Universidad Nacional del Nordeste, Corrientes, Argentina. She is currently continuing as an MS student in agronomy (plant physiology) at Kansas State University, focusing on untangling the yield gain evolution on sorghum during the last five decades.

P. V. V. Prasad is a university distinguished professor and director of the Sustainable Intensification Innovation Lab at Kansas State University. His research focuses on understanding responses of crops to changing environments; developing best management strategies to improve and protect yields; and improving livelihoods of people and providing food and nutritional security to smallholder farmers. He received his BS and MS degrees from Andhra Pradesh Agricultural University, India, and his PhD from the University of Reading, United Kingdom.

Laura Mayor is a research scientist at Corteva Research Station, Wamego, Kansas. She is a plant breeder dedicated to sorghum improvement and as the Sorghum North America Evaluation Zone (EZ) Lead for the High Plains market. She received her BS and MS degrees from the Universidad Nacional of Rosario, Santa Fe, Argentina, and her PhD in plant breeding from Iowa State University.

Mithila Jugulam is currently a professor at KSU with research and teaching responsibilities in weed physiology. She received her $\mathrm{PhD}$ and postdoctoral training at the University of Guelph, Canada. Her current research focuses toward understanding the mechanisms and genetic basis of herbicide resistance in weeds. She teaches courses related to herbicide interactions and weed physiology at KSU. She serves as an associate editor of Pest Management Science and Weed Science journals.

Ignacio A. Ciampitti is a professor in the Department of Agronomy and director for the Digital Tools, Geospatial and Farming Systems Consortium, Sustainable Intensification Innovation Lab at Kansas State University. His research focuses on the integration of the main mechanisms linked to plant responses to the environment with remote sensing and crop growth modeling, focusing on quantitative agronomy. He received his BS and MS degrees from the University of Buenos Aires, Argentina, and his PhD from Purdue University. 